\title{
La fraternidad agustiniana tras el Vaticano II: acentos y desafíos*
}

\author{
ViCTOR LOZANO ROLDÁN*
}

RESUMEN: A partir de la situación de crisis que atraviesa hoy la VR, el autor destaca el valor de la fraternidad, un elemento característico de la vida consagrada en general y del carisma agustiniano en particular, como una clave fundamental para la revitalización de la vida y misión de las comunidades religiosas.

PALABRAS CLAVE: Vida Religiosa - Agustinos - Fraternidad - Comunidad Agustiniana.

ABSTRACT: From the situation of crisis that nowadays Religious Life is going through, the author of this paper highlights the value of fraternity. It is a characteristic element of consacrated life in general and particularly of the augustinian charism. It is also a fundamental key for the renewal of the life and mission of religious communities.

KEY WORDS: Religious Life - Augustinians - Fraternity - Augustinian Community.

\section{A. CONTEXTO DE CAMBIO Y DE CRISIS}

El primer terremoto que trastornó al mundo -la agricultura- arrastró a los primeros nómadas de las cavernas a los valles. El segundo terremoto -la industria-convulsionó la sociedad rural. El tercero y de gran intensidad, que

* Este artículo es una nueva presentación actualizada del publicado por el autor para la serie "Temas de OALA" n. 7, Iquitos 2009.

* Presidente de OALA (Organización de los Agustinos de Latino América). Iquitos, Perú. 
estamos viviendo -la informática - ha producido un nuevo periodo de la historia caracterizado por la globalización, con "cambios profundos y acelerados" (GS 4). Ya no sólo vivimos una época de cambios, sino un verdadero cambio de época, donde la humanidad ha progresado más en el orden científico, en los últimos cincuenta años, que en todos los milenios anteriores.

En el aspecto religioso, el movimiento New Âge ha calado en nuestro entorno. Dios es sustituido por una vaga fuerza cósmica, la gracia, por la energía y la salvación, por la realización personal inmediata. El secularismo moderno aporta tres elementos característicos de toda religión: pecado, soteriología-salvación y paraíso. Se pone el acento no en el pecado, sino en la angustia y soledad de la persona actual. Se considera salvación a la autorrealización personal e individual. Y el principio del placer inmediato reemplaza al paraíso. No hay espacio para una visión de comunidad, para una vida de entrega. No se menciona jamás la cruz. Todo, excepto el sacrificio, está permitido. La gratificación tiene que ser inmediata, imposible un compromiso permanente. La religión está bien, pero en la sacristía, confinada a la esfera individual para que no interfiera en el placer, los proyectos individuales y el lucro. Paul Ricoeur describe la sociedad moderna como de producción y consumo. El consumo es una religión, los grandes almacenes son los templos modernos, dios es el dinero, la trascendencia la búsqueda de la eterna juventud. Otros hablan de la cultura clínex de usar y tirar.

Tras el Concilio Vaticano II la vida religiosa (VR) ha entrado en un proceso de crisis que muchos creen irreversible. La crisis se ha evidenciado principalmente por la disminución del número de religiosos/as. Cierto que hay países donde están llenos los noviciados, pero todo hace indicar que los tiempos de gloria han llegado a su término, porque el mundo moderno y secularizado conquistará hasta el último rincón del planeta. El Concilio influyó en la crisis al hacer un llamado a la santidad para todo el pueblo (cf. LG, cap. V), quitando a los religiosos/as la bandera que creían tener en exclusiva. El impacto de sentirse Iglesia sobre todo, difuminó las espiritualidades propias -de los presbíteros, de los laicos, de los/as consagrados/as-. Y también sucedió que las nuevas sensibilidades sobre la dignidad y realización de las personas acabó con muchos supuestos inamovibles. Finalmente, la disminución de la autoridad de la Iglesia y de su Magisterio, la impaciencia de muchos ante los cambios y los problemas de adaptación de la misión propia al carisma, en un mundo sometido al cambio acelerado, hicieron el resto.

La conclusión que saca la mayoría ante la actual situación es que estamos en decadencia; que la VR está en declive sin remedio. Estamos 
atravesando por una crisis de identidad y de sentido sin precedentes históricos ¿Causas? ¿Remedios? Muchos se preguntan si no es la misma VR, traicionada desde dentro por nosotros mismos, la que está produciendo en su seno sus propias llagas espirituales y psicológicas. En los últimos años hemos intentado un proceso de revitalización, de aggiornamento, de refundación, de redes, y no sé cuantos términos más... y da la impresión que no ha tenido los resultados que se esperaban.

Esta crisis nos dice, sin embargo, que entramos en la posibilidad de una nueva etapa diferente, grande y más profunda, aunque no tenga como exponente la magnitud en números. En este contexto, ¿cuál es la respuesta de la Iglesia y de la VR a esta situación? Por encima de todo, seguimos creyendo en las palabras de Jesús: "yo estaré con ustedes todos los días hasta el fin del mundo" (Mt 28,20). A pesar de las limitaciones y pecados seguiremos cumpliendo el mandato de Jesús de anunciar el Reino de Dios a los hombres de todos los tiempos.

\section{B. PunTO DE PARTIDA: LLAMAdO A LA COMUNIÓN}

\section{Agustín versus Michael Jackson}

La gran lección de vida y hechos que nos deja el gran Michael Jackson, al margen de su genialidad como bailarín y cantante, es que nada es suficiente cuando se tiene una sed vital insaciable y se trata de saciarla por el camino equivocado. Definitivamente el gran Jacko quiso ganar el cielo y saciar su sed de inmortalidad pero, como muchos hombres hoy, puso su corazón en un tesoro equivocado (cf. Mt 6,21) y se equivocó de lleno. Esta sed no se llena con cosas materiales... Lo dijo el Maestro: "No se atormenten por su vida con cuestiones de alimentos, ni por su cuerpo con cuestiones de ropa. Miren que la vida es más que el alimento y el cuerpo más que el vestido... Busquen más bien el Reino y se les darán también esas cosas" (Lc 12,22-23,31).

Sin embargo, todos sus lujos y extravagancias no lograron evitarle una vida torturada, miserable y, a la postre, probablemente infeliz. En realidad, el indiscutido Rey del Pop se convirtió en un prisionero recluido en su castillo de Neverland, condenado a la soledad más atroz, la que uno mismo se impone al aislarse del mundo y dedicarse al culto de su ego. Sus excesos, su obsesión por frenar el envejecimiento, su extravagante modo de vida le pasaron factura y le condujeron finalmente, y más rápido de lo previsto, a lo que tanto temía y trataba de evitar: la muerte. 
Traigo aquí esta figura más que nada porque es de alguna manera la imagen de nuestro tiempo: el hombre aislado, individualista, negador de lo comunitario, centrado en sí mismo, enceguecido por el ego. En esta línea, hoy, vemos como arrasa a nivel mundial el boom del Chat, el Facebook, el Youtube, el Twitter, el móvil... Millones de personas con hambre de comunicación, de amistad, de relación, de ser significativos para otros pero, a la postre, aislados. Vivimos en un mundo intercomunicado pero vacío de comunión. ¡En este clima cómo no va a ser atractivo el proyecto de Agustín propulsor de comunidad, abierto a Dios y a los hermanos, sembrador de amistad, de comunión, de amor personalizado! El mundo está pidiendo a gritos el modelo agustiniano.

\section{2. ¿Por qué Agustín no pasa de moda?}

¿Por qué su perenne actualidad? ¿Cómo se puede llamar "hombre moderno" a un personaje del s. IV? Pues bien, fundamentalmente por su visión integradora del hombre. Agustín plasmó una visión existencial y dinámica del hombre. En él ya encontramos el esquema antropológico del Vaticano II. Para impulsar su modelo comunitario bebe en las fuentes del Evangelio y en la cultura greco-romana. De ese encuentro brota la forma más idónea de entender el paso del yo al nosotros en mutua fecundidad. Sitúa la vida de Dios en el hombre, en el centro de las relaciones humanas. Nos dice que el hombre crece en la medida en que se relaciona y se deja habitar por Dios. Si contemplamos a Agustín y al hombre en sus dimensiones de interioridad, de trascendencia, de fraternidad y de amistad, en seguida descubrimos al testigo para el ser humano de nuestro tiempo. Es más, podríamos decir, que Agustín entronca con los personalismos de nuestro tiempo (E. Mounier) porque recupera al sujeto en su dimensión individual y comunitaria, el otro, entendido como el compañero de los destinos de mi libertad (G. Marcel).

Pero Agustín le añade algo: Cristo es la referencia obligada para todo aquel que, desde lo humano y desde la fe, asume al hombre total. Es decir, ha devenido en fracaso o en imposible, realizar la utopía de poner el bien común por encima el propio, si la persona no se abre a la fe, al Trascendente. Las relaciones humanas cambian de signo si el espacio humano, personal y comunitario, es habitado por la Trinidad ${ }^{1}$. Pero hoy estamos

${ }^{1}$ Cf. C. Morán, Comunidad y fraternidad (Cuadernos de Espiritualidad Agustiniana 11), FAE, Madrid 2003. 
marcados más por la civilización del tener y del consumir que por la del ser y la del amor. La crisis de la sociedad se refleja en esa nefasta separación de ética y conducta.

Desde luego, la auténtica vida comunitaria no consiste en estar juntos, sino en estar unidos. "La vida religiosa es, ante todo, comunión. Ella realiza el intento fecundante atractivo y siempre renovador, de fundar sobre la tierra un tipo de amistad que liga a los creyentes desde Cristo, por encima de los lazos de la carne y de la sangre"2. Entrar en comunión con Dios y con los hermanos es la más alta vocación del hombre (cf. La vida fraterna en comunidad-VFC- n. 9). Hoy la Iglesia nos llama a la vida de comunión a imitación de la Trinidad (cf. Novo Millennio Ineunte -NMIn. 43; Caminar desde Cristo -CdC- n. 29), que implica la comunión con Dios, con los hombres y con el mundo. Desde las primeras líneas de nuestra Regla el modelo de la primera comunidad cristiana está allí presente para marcar nuestro camino y especificidad: "tener una sola alma y un solo corazón (Hch 4,32) hacia Dios" (Regla I, 3).

Las raíces últimas de nuestra comunidad se hunden en el misterio de Dios que, por ser Trinidad, es comunión en el amor. Agustín sabe que este proyecto de vivir la comunión está enraizado en el Dios que es, básicamente, comunión trinitaria. El deseo de Jesús "que todos lleguen a ser uno" (Jn 17,21) con el Padre y el Espíritu, lo va a ir desarrollando consciente de que la motivación última de vivir en comunión surge de esta relación trinitaria. El camino para poder conseguir esta unidad ideal, viene mediatizado por la incorporación a la vida misma de Dios Trinidad.

"La participación en la comunión trinitaria puede trasformar las relaciones humanas creando un nuevo tipo de solidaridad" (Vita Consecrata -VC-41). "De esta manera, tu alma no es propia tuya, sino de todos los hermanos, cuyas almas también son tuyas; o mejor, sus almas con la tuya no son varias almas, sino una única alma de Cristo" (Carta 243, 4). Sólo saben habitar en unidad, aquellos en quienes se halla la gracia de Cristo y eso se manifiesta en la praxis de la fraternidad y de la comunidad. En quienes no cohabita la caridad, aparece la murmuración, el odio, la turbulencia, la discordia y la división ${ }^{3}$. Para poder llegar a esta unidad concorde se necesita "hacer un solo hombre, o sea, muchos cuerpos, pero no

${ }^{2}$ X. PIKAZA, Palabra de amor, Sígueme, Salamanca 1982.

${ }^{3}$ S. Agustín, Comentario a los Salmos 132,12 en Obras de San Agustín XXII, BAC, Madrid 1967, p. 477. 
muchas almas; muchos cuerpos, pero no muchos corazones. Así se dirá con justeza monos, es decir, uno solo"4.

La Exhortación apostólica VC (1996) define la comunidad religiosa como "espacio habitado por la Trinidad". La participación en la comunión trinitaria puede trasformar las relaciones humanas creando un nuevo tipo de solidaridad (VC 41), un espacio teologal en el que se puede experimentar la presencia mística del Resucitado. Por otra parte, la comunidad religiosa, antes que religiosa es comunidad: espacio humano, ser-con-losotros. Por eso el documento VFC (1994), además de hacer alusión a textos evangélicos, nos habla de valores humanos fundamentales para la vida en comunidad: educación, amabilidad, sinceridad, dominio de sí, delicadeza, sentido del humor, espíritu de participación... Por otra parte, la orientación del amor en la vida es lo que motiva el sentido de la existencia: "cada uno vive según lo que ama"s. La insistencia de Agustín en la amistad a través de su trayectoria vital, le mueve a buscar siempre la compañía de sus más íntimos compañeros ${ }^{6}$. La deficiencia en la madurez está en la base de los conflictos comunitarios e interpersonales. La raíz del conflicto es humana, conflicto entre consciente e inconsciente. La calidad de las personas da lugar a la calidad comunitaria, por eso no habrá comunidades maduras sin personas maduras.

\section{REDESCUBRIENDO NUESTRA VIDA AGUSTINIANA}

El mundo neocapitalista actual, que mira la realidad en términos de producción y consumo, de estadísticas y números, nos afectó también a nosotros: hemos sido seducidos por la grandeza de los números. Sin embargo la VR no se mide por el tamaño de su directorio de casas y miembros. En la vida de fraternidad importan más la cualidad que la cantidad. Jean Chittister asegura que "gracias a la disminución numérica, la VR ha vuelto a vivir de nuevo. Esta crisis nos devuelve a Dios". Este debiera ser el mensaje optimista de la revitalización de la VR hoy. Por otra parte, el anhelo de Jesús: "La mies es mucha y los obreros pocos" (Mt 9,37; Lc 10,2), nos ha confundido. Hemos interpretado que se necesitan

\footnotetext{
${ }^{4}$ Ibid., 132, 6, p. 471.

${ }^{5}$ ID., La Trinidad 13,20,26 en Obras de San Agustín V, BAC, Madrid 1948, p. 763. Cf. C. Morán, Comunidad y fraternidad, p. 5.

${ }^{6}$ Cf. ID., Confesiones 4,4,7-9, (BAC minor 70), Madrid 1986, pp. 107-110.

${ }^{7}$ Cf. J. ChitTister, The Fire in these Ashes, A Spirituality of Contemporary Religious Life, Kansas City 1995.
} 
más vocaciones y religiosas y creo que no es así del todo. Jesús no estaba pensando que se necesitaban más hombres y mujeres que hagan votos de pobreza, castidad y obediencia. Los religiosos/as no somos los únicos obreros en su viña. Y es que siempre se había pensado que la única manera de trabajar por la Iglesia de Jesús era a través del sacerdocio o de la VR. Cierto que se necesitan sacerdotes y religiosos, pero también otros ministerios porque la vida consagrada no es ni un ministerio, ni un trabajo, ni un apostolado: es un estilo, una forma de vivir. Vivimos en una cultura que no estima la fantasía, se limita a tolerarla. Porque muchos quieren que la fe y la religión sean utilitarias y funcionales. Y ahí entrábamos los religiosos: que nos valoraban por nuestro quehacer más que por nuestro ser.

Y no hemos sido llamados para hacer algo, sino para ser algo, para ser testigos proféticos en el mundo, adoptando una vida que imita a Jesús y, como consecuencia -y como cualquier otro cristiano-, llamados también a ser obreros en la mies. Hay un hecho al que ya nos hemos acostumbrado: antes nuestros trabajos eran nuestro apostolado y hoy, por la disminución de efectivos, los están haciendo los laicos. Si antes casi todos los profesores de nuestros colegios eran religiosos, hoy somos una minoría insignificante. Pero los trabajos y los apostolados siguen adelante. ¿Por qué lamentarlo? ¿Por qué ver en ello un retroceso? Más bien es una oportunidad para redescubrir nuestro papel, lo que significa ser agustino. No podemos medir la providencia con mentalidad humana. Lo que consideramos una desgracia puede convertirse en algo mejor y diferente. Creo que hoy Dios nos está pidiendo otra cosa, otra frontera, otra cumbre.

Es importantísimo que la VR llegue a asimilar en la teoría y en la práctica que su mayor servicio a la Iglesia no es lo que hace, sino lo que es y el estilo con que hace lo que hace. Como dice Erik Fromm en Ser o tener "En el NT la dicha es el fruto de haber renunciado a tener, mientras que la tristeza es el estado de ánimo del que se aferra a sus posesiones".

El carisma agustiniano se resume básicamente en el amor a Dios sin condiciones, que une las almas y los corazones de los hermanos en convivencia comunitaria. Amor que se difunde hacia todos los hombres, para ganarlos unirlos en Cristo dentro de su Iglesia. "Si aman a Dios, arrastren a todos al amor de Dios... arrastren a cuantos puedan, exhortando, orando, dialogando, dando razones, con mansedumbre, con amabilidad, arrástrenlos al amor" (Sermón 2,6-7). Si Agustín y sus predecesores en el monacato, Pacomio y Basilio, conceden un lugar preponderante a la vida en comunidad, ello se debe a que ven en la orientación hacia el yo y en el 
individualismo el obstáculo principal para que se cumpla el Evangelio. La comunidad es el amor al próximo en acción, de ahí su peso ${ }^{8}$. Es querer juntos lo que quiere Dios. El hermano pasa a ser, entonces, el lugar teológico, o sea, lugar del encuentro con Dios, por tanto la fraternidad es el verdadero culto a Dios.

La comunión de bienes materiales y espirituales es tan importante en la vida común agustiniana que se convierte en signo de validez de nuestra fraternidad, ya que el fundamento de la vida agustiniana es la vida común. La vida de comunidad debería ser la síntesis integradora donde toda la vida fraterna se hace posible y real. Esto quiere decir que no podemos dejar afuera los aspectos más importantes, ni acentuar unos en detrimento de otros, so pena de estar traicionando nuestro carisma. El equilibrio de una comunidad en los tres aspectos de oración-contemplación, convivencia y misión centran las características de la comunidad agustiniana.

En la vida común tiene gran peso la amistad, la comunión de bienes, la oración, el estudio y el servicio a la Iglesia. No se trata de conseguir la perfección individual a través de normas conventuales y ejercicios ascéticos, sino más bien de buscar la fraternidad y la caridad y, en ellas y a través de ellas, alcanzar la sabiduría, la perfección y la madurez espiritual y cristiana9.

La comunidad en fraternidad, orientada hacia Dios, recibe de esta orientación su plenitud de sentido. En el centro de la comunidad hay que considerar el ingrediente infaltable de la amistad, capaz de cohesionar las diferencias entre los hermanos. La ascesis en el proyecto agustiniano ya está más humanizada y frecuentemente tiene una proyección social. En este modelo son fundamentales las relaciones humanas en el amor recíproco, el perdón, etc. Por eso importan más el perdón que las penitencias, más la alegría en fraternidad que la ascesis (entendida como renuncia). Finalmente, la comunidad se realiza no sólo en la oración y el estudio, sino también, como se ha dicho, en el servicio pastoral ${ }^{10}$.

¿Cuál es la tarea típica de la comunidad agustiniana? ¿Colegios, parroquias, misiones, estudios-investigación, contemplación? Agustín nunca quiso dar a sus comunidades un objetivo externo concreto. Puede ser cualquiera, pero con las características antedichas.

8 T. VAn BAVEl, Agustín de Hipona. Regla para la comunidad (Serie Verde 5), OALA, Iquitos 1986, pp. 39-50 (aquí 42); ID., Carisma: comunidad. La comunidad como lugar para el Señor (Tradere 4), Religión y Cultura, Madrid 2004, especialmente pp. 115-134.

${ }^{9}$ Cf. ID., Agustín de Hipona. Regla para la comunidad, pp. 51-67; ID., Carisma: comunidad, pp. 135-160.

${ }^{10}$ Cf. ID., Agustín de Hipona. Regla para la comunidad, pp. 75-83; ID., Carisma: comunidad, pp. 161-180. 


\section{Retos o desafíos de la VR Agustiniana hoy}

Los valores presentes en el Evangelio son tantos, que tratar de vivirlos todos de manera profunda es prácticamente imposible. En realidad. Bastaría vivir uno en radicalidad y profundidad para tocarlos a todos. Así, san Antonio trató de vivir radicalmente la invitación de Jesús: "ve y vende todo lo que tienes y dalo a los pobres; luego ven y sígueme" (Mc 10,21 par.). San Agustín, por su parte, propuso el ideal en su Regla a partir de las primeras comunidades cristianas: vivir con "una sola alma y un solo corazón" (Hch 4,32; cf. Regla I,3). Vivir este ideal es estar en comunión con todos los valores del Evangelio.

De la misma forma, los retos de la VR agustiniana hoy son muchos ${ }^{11}$. Podemos poner largas listas y siempre alguien encontrará más retos y desafíos. Son tantos que nos perderíamos y no profundizaríamos en ninguno. Por eso he optado por señalar sólo tres; los que considero más importantes porque enfrentando estos retos estaremos tocando y rescatando el resto, estaremos en el camino correcto de la revitalización.

\section{Volver a Jesucristo. Volver a Dios}

¿Cuál es nuestro papel hoy? ¿Trabajar bien? ¿Mantener nuestros apostolados tradicionales con solvencia? No. Nuestro papel principal es testimoniar a Dios además de hablar de El. Hoy Dios ha pasado a ser el contenido prioritario de predicación y de testimonio, especialmente en Europa. Y esto porque Dios y su reinado están ausentes cada vez más en la vida de los hombres, sobre todo en los que tienen cuenta corriente. Dios no está ya ni en el arte moderno, ni en la prensa, ni en RTV (Radiotelevisión), y lo que no sale en los medios no existe para la gente. Nuestra tarea es desequilibrar ese mundo aparentemente feliz, pero de felicidad falsa y amenazada, y reflejar la sospecha de un mundo trascendente de felicidad plena. Reflejar la buena noticia de Dios desde la vida.

Hoy es la fe en Dios la amenazada tras la predicción filosófica de su muerte. Muchos hombres hoy viven al margen de Dios totalmente, incluso le amenazan y piden cuentas acerca de su proceder. Cobra vigencia la palabra de Jesús: “cuando venga el Hijo del hombre, ¿encontrará fe en la

${ }^{11}$ Cf. Documento "La renovación de la vida agustiniana", 2.2. Desafíos en ORDEN DE San Agustín, Capítulo General Ordinario 2007. Documentos y determinaciones, Roma 2007, pp. 20-22. 
tierra?" (Lc 18,8). Incluso Jesús ha dejado de ser acogido, reconocido, amado. Los Beatles se atrevieron a decir, ya en los 60, que eran más famosos que Jesucristo. Hoy cunde la desafección religiosa y la indiferencia, se extiende la increencia, avanza el ateísmo práctico. La ausencia de Dios constituye una verdadera tragedia social, por tanto, se trata de saber que tenemos un gran reto: comunicar esperanza al mundo de hoy. Que la esperanza y la trascendencia no están en estirarse la piel, ni en la eterna juventud, ni en el poder, ni en el dinero, ni en la fama. El mismo Benedicto XVI dijo en un discurso: "la Iglesia debe hablar de muchas cosas... pero su tema auténtico, y en cierto sentido único, es Dios. El gran problema de occidente es precisamente el olvido de Dios. ¿Estamos convencidos de ello?"12.

He ahí un reto para nuestra VR; he ahí un papel central: hablar de Dios en un mundo que le ha puesto fecha de caducidad. Ya sabemos que la fe no quita, confiere humanidad. Re-liga al hombre para liberarlo de ídolos y fantasmas. Fe, esperanza y amor no son quimeras, sino dimensiones gratificantes de la condición humana. No son los deseos humanos los que crean a Dios, sino que es Dios quien ha creado al hombre con capacidad de pensar, desear y relacionarse con Él. Dios enriquece al hombre, lo completa. Pero el mundo de la increencia-indiferencia está ahí.

\subsection{Acentos}

¿Cómo bajar a Dios de los cielos para que lo perciban en nuestra vida los hombres de hoy? Veamos algunos acentos:

a) Evangelizar. Pablo VI nos dice: "los religiosos tienen en su vida consagrada un medio privilegiado de evangelización eficaz. A través de su ser más íntimo se sitúan dentro del dinamismo de la Iglesia, sedienta de absoluto, de Dios, llamada a la santidad. Es de esa santidad de la que ellos dan testimonio. Encarnan la Iglesia deseosa de entrega al radicalismo de las bienaventuranzas, signo de total disponibilidad" (Evangelii Nuntiandi n. 9). Allí donde el proyecto primero es tener, serán una contracultura. Dicen a gritos que lo más importante es ser: ser hermanos, verdaderamente hijos de Dios. Hemos optado por ser presencia de Cristo libre ante el poder, el dinero, los honores y la ambición humana.

12 Benedicto XVI, Discurso a la Curia romana ante la Navidad (2006) en Ecclesia 3343-3344 (6 y 13 de enero de 2007). Citado por L. A. Montes Peral, "Hablar de Dios hoy y testimoniarlo": Estudio Agustiniano 44 (2009), 5-33. 
b) Testimonio personal y comunitario. Solo convence quien es, no quien aparenta ser. La apariencia nos delata por todas partes. ¿Cuál es la mejor catequesis sobre Dios? La presencia de una comunidad verdadera donde las personas se aman, se honran los unos en los otros, se valoran, se respetan... El testimonio coherente de todos y cada uno de los hermanos. Hoy la gente se siente poco impactada por una comunidad sólo espiritual, y peor si la acompañan señales de inmadurez; en cambio, valora la comunidad humana y humanizadora que es donde Dios se manifiesta.

c) La alegría. El hombre es para el hombre salvación y consuelo, puesto que es esencialmente humano y ninguna virtud es tan apropiada al hombre de hoy como esta: suavizar lo más posible las penas de los otros, hacer desaparecer la tristeza, devolver la alegría de vivir, es decir, el placer de vivir. Cómo arrastra una comunidad donde hay verdadera alegría, donde se han desterrado los rostros adustos, donde se reza, se trabaja, se recrea juntos. La gente se divierte, se jaranea, toma, pero la procesión va por dentro. La alegría verdadera, la que brota de la paz interior, es revolucionaria: “... Otras cosas había que cautivaban más fuertemente mi alma con ellos, como era conversar, reir, servirnos mutuamente con agrado. Leer juntos libros amenos, bromear unos con otros y divertirnos en compañía..."13.

d) Ser portadores de esperanza. La falta de esperanza cierra el camino hacia la felicidad... "de todos los rasgos que caracterizan al hombre de hoy, el más preocupante es la pérdida de la esperanza" (J. A. Pagola). Hay que amar el mundo porque es el solar donde tenemos que levantar el Reino de Dios. Estamos para trasformar la realidad. Y realidad no es un concepto en clave, sino una palabra simple y llana que indica, desde una óptica teológica, el campo donde Dios se encarna, el campo que Dios cultiva y en el que nos toca vivir y redimir.

e) Los gestos de misericordia. El hombre está lleno de heridas y sufrimientos. La ciencia elimina muchos dolores, pero no la angustia. Cómo arrastra y causa admiración en la gente una comunidad de hermanos samaritanos, repitiendo los gestos compasivos y misericordiosos de Jesús. Con oído de inclusión para los pobres, enfermos, marginados... Cómo influye esta visión en el pueblo, cómo deja mudos a los no creyentes.

f) Justicia y paz. Para nosotros la pobreza y la injusticia deben ser un reto. Esto implica sencillez de vida... No podemos vivir instalados con fama de ricos. Eso es demoledor. Habrá que optar por compartir nuestros

${ }^{13}$ San Agustín, Confesiones 4,8,13, p. 114-115. 
bienes, tener proyectos que sean signo, que indiquen con quién estamos, opción en unos casos y sensibilidad siempre hacia el mundo de los pobres y una postura insobornable a favor de la justicia, la equidad, la simetría, la igualdad, la distribución universal de los bienes, graficando con nuestra vida el ideal de la primera comunidad cristiana: "entre ellos ninguno pasaba necesidad" (Hch 4,34).

\subsection{Nuestras llagas}

Estamos saturados de análisis, diagnósticos y propuestas, artículos valientes y audaces. Sin embargo, nada cambia verdaderamente entre nosotros. Para escribir estas líneas tuve que leer una veintena de folletos y artículos diversos, excelentes todos. Pero todo queda en el disco duro o pasa a la biblioteca porque llegan otras novedades. Nuestra vida es esencialmente poética, apasionada, parabólica. La historia nos ha castrado y hemos confundido esa castración con los votos. Lo nuestro es lo simbólico, la intimidad con el misterio y la irremediable utopía de la fraternidad adobada por el amor. Nuestra vida es anunciadora de felicidad y hemos enmudecido y encarcelado esa buena noticia con un mensaje que a nadie molesta ni llama la atención. Tenemos que vivir nuestra fraternidad como una pasión: la pasión de Jesús. Hoy morimos por demasiado prudentes y sabios; y el Espíritu es locura, y no encuentra brecha para penetrarnos y movilizarnos y arriesgar. Hoy es tiempo más de visionarios que de administradores del tesoro. Tenemos que volver a lo primigenio; elegir, como Pedro, entre obedecer a Dios o a los hombres. Obedecer a Dios trae conflictos, obedecer a los hombres lleva a traiciones. Es preciso escuchar a ese Viento que no sabes ni "de dónde viene ni a dónde va" (Jn 3,8).

\subsection{Reflexión}

No se trata de buscar a ciegas a Dios, sino de buscarlo allí donde se encuentra: en la humanidad de su Hijo. Contemplar al Hijo es contemplar al Padre. Porque “a Dios nadie le vio jamás, el Hijo único que es Dios, y que está en el seno del Padre, nos lo ha dado a conocer" (Jn 1,18). Y por Él en el hermano, en la comunidad y en los pobres.

Nosotros al seguir a Jesús damos testimonio de que Dios está con nosotros, que nos hemos encontrado con Él, que lo hemos experimentado, incluso, lo hemos bajado del cielo, viviendo sus valores -unitas, caritas, veritas-, que hemos adoptado el estilo de vida de su Hijo Jesús y proseguimos su causa: la causa del Reino. La increencia pone al hombre frente a un muro ciego, Jesús le abre las ventanas al infinito. En este contexto de 
marcada indiferencia o manifiesta increencia, Dios debe ser "bandera primera" de la VR.

Cuando la Iglesia se acomodó excesivamente con este mundo la VR nació para ser memoria de su dimensión escatológica (monaquismo). Ahora cuando domina la tendencia opuesta del alejamiento, la VR debe realizar nuevos compromisos con el mundo, abriendo nuevas fronteras. Porque la VR no es un oficio, ni un estilo ascético, ni una espiritualidad, sino un carisma parabólico: ser Iglesia en la "anormalidad desapegada". Estamos llamados hoy a recuperar el desierto (donde no hay nadie, sólo Dios), irnos a la periferia (lejos del centro) y a la frontera (ir al riesgo) ${ }^{14}$. Ir hacia las pequeñas fraternidades insertas en el pueblo de Dios, pero con sentido universal, entregados a las dos grandes fronteras: la increencia o neopaganismo y la injusticia. E ir con marcado sentido de la gratuidad, de la gracia, del buen humor y de la paciencia histórica.

La derrota de la VR no vendrá por la disminución de efectivos, sino por la muerte de nuestro vínculo espiritual con el Señor y con nuestra personal vocación y misión (cf. VC 63). En un mundo en búsqueda del Trascendente solamente los religiosos/as que ardan con el fuego de Jesús en su dedicación al Reino pueden ser relevantes para la humanidad en este milenio.

\section{Volver a la comunidad en fraternidad}

La fraternidad cristiana sale al encuentro de tres necesidades psicológicas de todo ser humano vistas desde la perspectiva del Evangelio: $1^{\mathrm{a}}$ amar y ser amados. En el ágape que hunde sus raíces en Dios mismo (cf. 1Jn 4,8.16), encuentra un camino para su realización. $2^{\mathrm{a}}$ ser útiles, producir, que tiene su campo en la esperanza cristiana que lucha por la trasformación de la sociedad y del mundo. Y la $3^{\text {a }}$ que es comprender el sentido de la existencia, puede encontrar su realización en la fe que lleva a ver y a juzgar en grupo dialogante la realidad en que se vive ${ }^{15}$. Por eso la fraternidad siempre tendrá adeptos.

Nuestras características agustinianas más saltantes son la interioridad, la amistad y la comunión de vida, que apuntan a un cristianismo vivido apasionadamente, con sentido comunitario, capaz de realizar el

\footnotetext{
${ }^{14}$ Cf. J. Sobrino, Resurrección de la verdadera Iglesia, Sal Terrae, Santander 1981, p. 335 .

15 Cf. C. MACCISE, Los religiosos como signo de fraternidad, Bogotá 1997; ID., Un nuevo rostro de la vida consagrada (Frontera 45), ed. Frontera, Vitoria / Gasteiz 2004, pp. 47-60.
} 
encuentro con Dios y el servicio al hombre. Desde el comienzo de la Regla, la koinonia o comunión de la primera comunidad cristiana de Jerusalén es el elemento básico de la comunidad agustiniana: tener una sola alma y un solo corazón. Agustín añade, la expresión "hacia Dios".

Pero además, en toda persona humana existe una llamada a realizarse plenamente en su vivir con los demás. En todo hombre hay una inclinación, una llamada a la comunión y a la comunicación; el hombre es dialogal, llamado a compartir su vida con otros. Ser hombre es ser-con y su vivir un vivir-con. Un hombre-isla no es humano. E. Mounier dice que se podría afirmar que no existo sino en la medida en que existo para el otro. Mejor aun, ser es amar. Es más, no es posible encontrarse uno a sí mismo sino en y desde los demás ${ }^{16}$. Es decir, "necesitamos de los demás para ser nosotros mismos". En otras palabras, los amigos son una necesidad.

Si en la amistad se encuentra la felicidad, su búsqueda ha de ser considerada como otra de las exigencias del ser humano. Si la amistad no se entiende como la entendía Agustín -abierta a la trascendencia-, nunca podrá ser hallada del todo. La verdadera amistad no sólo es llamada, dice Agustín, sino también don y regalo del propio Dios: "No hay verdadera amistad sino entre aquellos a quienes Tú unes entre sí por medio de la caridad derramada en nuestros corazones por el Espíritu Santo que nos ha sido dado [Rm 5,5]" ${ }^{17}$. La vida sin amigos es un destierro para san Agustín, por eso la amistad constituye el ideal supremo de la vida agustiniana y es también un valor cristiano, dado que el "ámense los unos a los otros" es norma para todo creyente sin distinción.

Donde haya una comunidad inmersa en el gozo del Espíritu, la atención recíproca ayuda a superar la soledad y la incomunicación; contribuye a que todos se sientan corresponsables, y donde el perdón cicatriza las heridas y refuerza la comunión. "En comunidades de este tipo, la naturaleza del carisma encauza las energías, sostiene la fidelidad y orienta el trabajo apostólico de todos hacia la única misión” (VC 45). Esto es trabajar por la renovación. El "documento de Dublín" (1974) ya marcó esta convicción: "El Capítulo está convencido de que si nosotros los agustinos no conseguimos una renovación de la vida común a la luz del NT y del espíritu de san Agustín, el resto de nuestros problemas (crisis de vocaciones,

16 Cf. T. Viñas Román, La amistad en san Agustín (Cuadernos de Espiritualidad Agustiniana 1), FAE, Madrid 2003; ID., Los religiosos y las religiosas “ayer, hoy y mañana”. Reflexiones sobre la Vida Consagrada (Colección Sígueme 25), San Pablo, Madrid 2010.

${ }^{17}$ San Agustín, Confesiones 4,4,7, p. 107. 
crisis de identidad, problemas apostólicos, etc.) no se resolverán ni surgirá una nueva vitalidad en la Orden"18.

\subsection{Acentos}

La aspiración a una vida de comunidad más fraterna es un fenómeno universal entre los consagrados. Pero no vivimos juntos para simbolizar el amor, sino para vivirlo. La fraternidad busca una expresión más inmediata, un estilo de vida más acogedor y sencillo, en diálogo y participación. Es la amistad, la sinceridad y la madurez humana lo que hoy se valora más, pero siempre tendrá como base una relación de fe, pues es el Señor quien nos convoca a vivir juntos, por Él vivimos en comunidad y no por otra cosa.

Hoy sabemos que la comunidad no se improvisa; es un proceso. ¿Es una utopía vivir en comunidad? En verdad siempre se encuentran algunos "llaneros solitarios", pero lo normal es la preocupación por vivir comunitariamente. Y es que el hombre ha sido hecho a imagen de un Dios que es comunidad de personas. Por tanto, existir es coexistir. El hombre no puede realizarse sino es con los otros. Hoy, que nos vemos acosados, avasallados por una sociedad que masifica implacablemente la vida y disuelve a la persona - itantas vidas solitarias, no compartidas, con hambre de amistad... tanta gente valorada sólo por lo que produce!-, volver a la familia y a la fraternidad es un imperativo.

La predicación de Jesús se centra en el llamado a los hombres a formar la fraternidad del Reino. Hoy el mundo sufre el vacío de la fraternidad, por un lado, y por otro, la añora utópicamente. Si la VR tiene hoy un papel que desempeñar es el de crear, permitir, suscitar, animar y sostener comunidades de vida auténticamente fraterna; lo que el mundo espera de nosotros es que les mostremos la fuerza y la potencia creadora del amor que nos ha unido, sabiendo que, aunque los hilos sean frágiles, la trama hecha por el Espíritu no hay quien la rompa.

Si la comunidad religiosa llega a ser la matriz de la que nacen y donde llegan a plenitud hombres liberados de sí mismos, de su cerrazón, de sus egoísmos, desalientos, inconsistencias, de lo que retiene al hombre en la esclavitud, para estar unificados y serenos, gozosos en la espera del futuro, hermanos de todos... entonces seremos esperanza para el mundo. Los

18 ORden de SAn Agustín, Documentos del Capítulo General Intermedio 1974, III, n. 64. Citado también por ID., "Agustinos en la Iglesia para el mundo de hoy", n. 9 en Documentos del Capitulo General Intermedio 1998, Roma 1998, p. 15. 
hombres verían que la utopía es posible... y todo porque hemos creído en Cristo y en sus promesas.

A mejor vida de comunidad, más calidad de vida religiosa. La mejor y mayor profecía que podemos ofrecer hoy es la comunidad vivida en fraternidad. En un mundo donde la injusticia divide y destruye, donde todos luchan por el botín; nosotros optamos por ponernos al servicio los unos de los otros, compartiendo bienes, búsqueda y amistad orientados hacia Dios. Frente a un mundo desagarrado y agresivo, al que se le han muerto las ilusiones de fraternidad real, incapaz de soñar utopías; los religiosos tendremos que ser hombres y mujeres de paz, creadores de comunión, despertadores de esperanza. Si muchos viven como hermanos, aun siendo tan distintos, es que la fraternidad es posible. Y es posible porque es posible el amor a Dios que nos une y hermana. Es más, debe llegar a ser tan intensa, que terminemos "habitando los unos en los otros".

La caridad será el centro. Esta experiencia de caridad fraterna ya le llamó la atención a Agustín en Roma: "es la caridad que se observa principalmente entre sí; es la que regula su alimento, sus palabras, vestidos y semblante. Y les une y les concierta; su violación es a sus ojos ofensa al mismo Dios. Arrojan lejos de sí y rechazan todo lo que podría serle obstáculo; lo que la hiere no puede durar un solo día. Todos saben que Jesucristo y los apóstoles de tal modo la recomiendan que, si ella sola falta, todo es vacío y nada, y si ésta existe hay plenitud en todo" (Costumbres de la Iglesia y de los maniqueos 1,33,73). La caridad es la perla preciosa, la vida del hombre nuevo, el distintivo cristiano, el comienzo de la vida eterna. Y si la caridad viene adobada con buen humor y alegría, "miel sobre hojuelas".

También el "llevar las cargas los unos de los otros" es importante y significa el ayudarse a superar las imperfecciones personales mutuamente, con el fin de llegar a un progreso en las relaciones humanas. "Llevar las cargas" no es sólo soportar al hermano en sus defectos, sino también ayudarle en sus tareas concretas, involucrarnos en su vida y en su quehacer desde la caridad.

La vida consagrada es un profetismo, no sólo de palabras y gestos, sino existencial. Una profecía encarnada donde toda la vida es símbolo de la centralidad de Jesús y de los valores del Reino. Así, los consejos evangélicos que impugnan los ídolos de nuestra sociedad, se convierten en signos proféticos y escatológicos de los bienes futuros del Reino de Dios. El éxito o el fracaso dependerá de nuestro renovado y radical seguimiento de Cristo, de la docilidad al Espíritu Santo y del enraizamiento en la comunidad eclesial; del celo misionero, de la respuesta a los 
desafíos de hoy, y de la fidelidad a las exigencias de nuestro carisma propio.

\subsection{Nuestras llagas}

El riesgo que comporta un programa comunitario lo resumió Juan Berchmans: "Mi máxima penitencia es la vida común". Pero fue Voltaire quien escribió la leyenda negra de la comunidad: "vienen sin conocerse, viven sin amarse y mueren sin llorarse". Aun siendo leyenda negra, algo nos toca. Jesús, el Santo, se puso a la cola de los pecadores para ser bautizado en el Jordán, como un pecador más. Nosotros, a veces, nos creemos perfectos, subimos al estrado y pontificamos. Nosotros no matamos ni una mosca, no rompemos ni un plato. También a los religiosos nos va bien la gloria y el triunfo, nos gusta el incienso y la alabanza, que la gente hable bien de nosotros. ¿Tendremos que aprender algo de esa actitud de Jesús?, ¿no?

En todas partes hay religiosos poco vulnerables a la crítica constructiva, porfiados para imponer lo suyo, incapaces de escuchar al otro, escasamente sociables y excesivamente sensibles, susceptibles, con poca o nula capacidad de integración, diálogo y convivencia. Hay que ser exigentes a la hora de admitir candidatos para la vida comunitaria. No podemos poner minas anticomunitarias ni antipersonales en nuestras casas...

La comunidad puede predisponer a la persona para alcanzar la madurez vocacional, pero no puede causar ésta; el grupo puede favorecer el crecimiento, pero no producirlo. Lo que produce la madurez vocacional es la capacidad intra-psíquica de interiorizar los valores, la decisión libre y personal de modelar nuestros comportamientos con los valores que hemos profesado y no según temores o recompensas. Depende, pues, de las actitudes internas de cada uno. Una comunidad agustiniana no encuentra su justificación en sí misma, en sus obras, sino que se justifica si todo lo que hace es medio para hacer realidad los valores que la convocan $y$ trascienden: libres con respecto a los medios, pero vinculados a los fines.

Las llagas de nuestra VR están ahí y habría que ponerles terapias espirituales. No se trata de regresar a las glorias de la VR en sí, sino para permitirnos un reencuentro con la exigencia primigenia de nuestra vocación., es decir, en función del Reino. Así podremos ser como el pueblo de Israel en Babilonia, que no optó por el sueño restaurador de un templo de poder, sino por la esperanza de un pequeño resto, humilde y discreto que ande ante Dios convertido y purificado por la prueba que suscitó su propio pecado. 
$\mathrm{Si}$ es verdad aquello de que "a mayor calidad de vida comunitaria, mayor calidad de VR", sería conveniente reflexionar cómo andamos en esto. Porque el testimonio más negativo para la acción evangelizadora es el de una comunidad dividida, carente de espíritu fraterno, donde estallan las luchas y las divisiones entre los religiosos. Se puede tener la sospecha de que la decadencia que vivimos no es más que el resultado de haber fallado -flagrantemente- en la vida comunitaria. Hemos descubierto que es muy difícil vivir con tantas diferencias de edad, mentalidad, formación, cultura... Si no vivimos una vida cohesionada desde dentro, con momentos fuertes de expresión comunitaria, este deterioro irá creciendo.

Prioricemos la fraternidad ${ }^{19}$. Ya sabemos que la VR ha evolucionado. De sus orígenes monásticos y laicales, se abrió a una vida apostólica y sacerdotal. De unas tareas a otras. Eso que entonces fue impulso del Espíritu, hoy tiene sus limitaciones. Por ejemplo, que en muchas partes se valore la vida consagrada más por la actividad de los religiosos, que por su testimonio de vida; más por su trabajo pastoral, que por su fidelidad al carisma original. Se ha llegado a una "parroquialización", "clericalización" de la VR, hasta el punto de considerar incompleta la VR no sacerdotal. Craso error.

\subsection{Reflexión}

Lo hemos dicho más arriba, vivimos tiempos de intercomunicación, pero no de comunión. Es más, a pesar de los medios, abunda la soledad y la masificación anónima. Pues bien, la vida en comunidad responde a ese desafío de una manera vital. Agustín buscó siempre a los amigos; para él, vivir solo y sin amigos era la mayor de las orfandades. Así, optó por unas relaciones humanas basadas en la amistad, el compartir, el amor, el servir juntos, frente a los ídolos del tener posesivo, el poder dominador y el gozo narcisista. Los agustinos hoy estamos llamados a esto: ser signo de comunión y solidaridad en un mundo individualista e insolidario ${ }^{20}$.

El fundamento teológico de la fraternidad agustiniana sería instaurar la comunidad cristiana primitiva, la que surgió en Pentecostés. La frater-

${ }^{19}$ Según Timothy Radcliffe (ex Maestro General de los dominicos) sea cual sea el papel que uno desempeña en la VR, nunca puede ser más que uno de los hermanos. Y cuenta que cuando le preguntan qué hace ahora, responde: "hago lo que hacemos todos: ser un hermano" (T. Radcliffe, "Nuestra vocación más necesaria que nunca" en Religión Digital 29.01.2008).

${ }^{20}$ Cf. D. NATAL, "La comunidad agustiniana en la práctica" en Elementos de una formación agustiniana, Roma 2001, p. 319. 
nidad es consecuencia de la caridad, del amor, y en esto pinta mucho la gracia que, para Agustín, es un auxilio, un don permanente que otorga Dios, en ese constante proceso de divinización del hombre desde las relaciones humanas ${ }^{21}$. ¿Qué es lo que pretendemos al vivir en comunidad? Veamos tres modelos 22 :

1) Comunidad de observancia: es aquella donde las necesidades de los individuos se subordinan y adaptan a las de la comunidad. Donde cada cual desempeña las funciones que le encomiendan y se acomoda a ellas. Le mandan y obedece sin rechistar. Donde cada uno realiza las expectativas que los demás tienen sobre él. Es la comunidad la que dice cómo interpretar la realidad.

2) Comunidad de auto-realización: pone el acento en el individuo más que en la institución. La norma fundamental y orientadora es: la comunidad debe procurar que cada miembro satisfaga sus necesidades. La actividad debe respetar y valorar las dotes personales. La comunidad funciona si hace felices a los que viven en ella. La persona cuenta más que la estructura. Este modelo puso en crisis el modelo anterior, para favorecer la comunidad de vida.

3) Comunidad para el Reino: ¿la persona es para la comunidad o la comunidad, para la persona? Tenemos mal planteada la pregunta. La comunidad es para los valores. En nuestro caso para los valores cristiano-evangélico-agustinianos. La comunidad es el lugar de trascendencia, el espacio humano que nos sirve para mejor interiorizar los valores del Reino, que son los que fundamentan el por qué estamos juntos. La comunidad consiste en vivir en comunión para profundizar el compromiso vocacional y construir el Reino de Dios. Ésta es eficaz si se autotrasciende, si estimula a las personas a amar a Dios con todo el corazón y con toda la mente, y a comprometer a todos en la tarea.

Pero antes de ponernos al servicio de los demás, tenemos que ser nosotros mismos. Forjarnos un yo conocido. Desarrollar nuestra identidad que no es otra cosa que la capacidad de mantener la unidad y continuidad internas. Estabilidad emocional, madurez. Lo contrario es la falta de autoestima y la falta de compromiso con los valores agustinianos que se mani-

${ }^{21}$ Cf. N. Castellanos, San Agustín, pastor desde la fraternidad (Cuadernos de Espiritualidad Agustiniana 42), FAE, Madrid 2003.

${ }^{22}$ Cf. A. MAnenti, Vivir en comunidad. Aspectos psicológicos, Sal Terrae, Santander 1983, pp. 9-14. 
fiesta en la dispersión y en las inconsistencias. La comunidad es eficaz en la medida que favorezca esta consistencia interna: construirse a sí mismos para darse libremente a Dios. Es válida si permite a los religiosos conocerse realmente y conocer los valores por los que merece la pena perderse a sí mismos. Pero no olvidemos que las personas no nacen maduras, se hacen maduras; y las comunidades no existen, se construyen.

\section{Volver al equilibrio oración/acción}

Hay un consenso general en esto: el fin de nuestro estilo de vida no es otro que la búsqueda de Dios. Por buscar a Dios, san Antonio se fue al desierto, san Pacomio fundó sus cenobios y san Agustín se juntó con sus amigos para una vida común y fraterna. Es decir, por el hecho de ser religiosos, todos somos, primero y antes que nada, contemplativos. Y si falla esto, fallan las bases del edificio. Pues bien, si este es el fin de la VR agustiniana y cualquier otra, ¿no será una desviación y una traición el hecho de que todos estemos saturados de trabajo hasta decir basta, y que, de hecho, la búsqueda de Dios, la oración y la contemplación la dejemos en un segundo plano cuando debiera ser el primero? Se puede tener la impresión que el ministerio nos ha robado el carisma. Que las actividades que, en realidad, debieran ser importantes, pero secundarias, han llegado a cubrir casi todo el espacio, y que nuestro ser se ha visto desplazado, en muchos casos, por nuestro quehacer.

La búsqueda de Dios es una manera de vivir, una espiritualidad que intenta enfocar toda nuestra vida hacia Dios. Todo en nuestra comunidad tiene sentido si está centrado en Él. Nuestro testimonio no está en la tarea que hacemos, sino en ser testigos de la realidad de Dios, de la centralidad de nuestra fe en Él. Hoy vemos personas que hacen el bien sin referencias a Dios, y creyentes que viven en la práctica las antípodas de su fe. Por tanto, a nosotros se nos pide significarnos por la coherencia de lo que profesamos, por la búsqueda genuina y honesta de Dios, es decir, que nos tomamos tan en serio el tema, que siguiendo a Jesús, dejamos los valores-eje de este mundo. Ese será el signo de contradicción en medio de este mundo.

En un mundo donde cada vez Dios parece estar más ausente, aquí estará nuestro papel más genuino, nuestra piedra de toque y carro de arrastre, porque tras esa capa de duda o desdén emerge en el hombre contemporáneo una creciente hambre de paz, de silencio interior, de significado y de esperanza. Sólo seremos significativos si podemos ofrecer lo que la gente no tiene y necesita: paz, alegría y libertad interior; si mostramos signos de esperanza, porque, de hecho, Dios es la única esperan- 
za para todos, hoy y siempre, ante la felicidad amenazada. Y esta búsqueda de Dios no nos debe sacar del mundo. La realidad en que estamos insertos constituye el lugar teológico. No tenemos que distraer nuestra atención de este mundo para encontrar a Dios.

La clave de una profundización en la búsqueda de Dios es el autoconocimiento; y la clave de ése es el desprendimiento y el desapego. Sin un verdadero desapego del mundo será difícil amar. Desprendimiento significa libertad frente a las cosas que nos encadenan. ¿A qué estamos pegados los agustinos hoy?, ¿al pasado?, ¿a las costumbres?, ¿a los números?, $\succsim$ al trabajo?, ¿a la imagen?, ¿a labrarnos un nombre perenne?, ¿a parroquias, ministerios, colegios, apostolados?, ¿a nuestra reputación?, ¿tal vez a ciertas comodidades burguesas? El desapego nos deja libres para lo importante. Como María de Betania, debemos dejar la cocina para ponernos a los pies de Jesús (cf. Lc 10,39). Nuestro reto hoy es aprender a morir. Sólo quien asume la voluntad de morir está capacitado para volver a vivir de manera completamente nueva, porque como dijo el Maestro: "aquel que guarda su vida la perderá, pero quien se atreva a perderla por mí y el Evangelio, la salvará" (Mc 8,35 par.).

\subsection{Acentos}

La lógica de la comunidad que Jesús quiso era el servicio; la lógica del poder no tiene cabida en la comunidad de Jesús. En la comunidad del Reino no se puede buscar el culto a la personalidad: en ella es preciso unir la humildad al servicio: el mayor tiene que hacerse como el menor (cf. Mt 19,13-15). Tampoco la lógica de la facilidad, pues Jesús llama a "cargar con la cruz" (Mc 8,34 par.) y a renunciar hasta a la propia vida. Jesús exigía disponibilidad para el despojamiento total, para la vivencia en radicalidad del mandamiento del amor y para el cumplimiento dócil de la voluntad del Padre. Hoy la comunidad más apreciada es la que integra todas las dimensiones fundamentales: sentido humano, oración y vida interior, convivencia y amistad, sentido de la misión.

Habría que acentuar el que se nos vea rezar juntos ${ }^{23}$. Es un gran signo de comunión. Hacer el esfuerzo de comer juntos. Cuando Jesús amaba a alguien no le echaba un discurso, se iba a comer con él. Comer juntos es una opción de amistad y de unión. El trabajar juntos, si es posible; si no,

23 "Nos ven trabajar, animar la actividad parroquial o educativa, movernos con prisa de un lugar a otro, pero ¿nos ven orar?” (ORDEN DE SAN Agustín, “Agustinos en la Iglesia para el mundo de hoy", n. 3, p. 9). 
entender que el trabajo es comunitario y dar cuenta de él. Tener un espacio diario de silencio y meditación innegociable para que Dios sea quien tenga la primera y la última palabra, no nosotros. Y finalmente, el estudio, importante para dar respuestas profundas al hombre de hoy. Y poner acento en la misión. La comunidad como base de aprovisionamiento, pero en función de la acción, de la misión, del servicio a la Iglesia.

La comunidad ha de ser una escuela de realismo y de ideales, donde lo primero que busca es cambiar el corazón y luego las estructuras. Por eso nuestro símbolo es el corazón. Cada uno es lo que es su amor. Toda comunidad bien llevada es una parábola de alternativa social porque propone con su vida la realización de las bienaventuranzas. La comunidad es "lugar de perdón y fiesta" (J. Vanier). En la comida y en la fiesta se juntan la alegría de comer y beber y compartir la vida fraterna en la gran familia del Reino (cf. Lc 22,28). Fiesta que anima, sí; pero que también compromete seriamente.

\subsection{Nuestras llagas}

En lugar de llenar el vacío de nuestras vidas con futilidades; en vez de refugiarnos en el activismo o en la resignación; en vez de buscar falsas seguridades en estructuras y expresiones anticuadas, debemos renovar nuestro "primer amor" (Ap 2,4), nuestra pasión por Jesús y por su comunidad. Sin eso seremos irrelevantes y la decadencia seguirá en curso. Si tenemos que ir contra corriente no es porque seamos sectarios, sino porque tenemos una propuesta alternativa: Jesús, su Reino, la fraternidad. La VR tiene su origen en el Espíritu del Resucitado y, como todo carisma, ha sido dado para la Iglesia y para el mundo, no para mirarnos el ombligo.

Como dice Jean Vanier: "la vida comunitaria está ahí para ayudarme, no a huir de la profunda herida de mi soledad, sino para hacerme permanecer en la realidad del amor, para crecer poco a poco en la curación de mis ilusiones y mis egoísmos, convirtiéndome yo mismo en pan para los demás. Estamos en la vida comunitaria unos para los otros, para crecer juntos y para abrir las propias heridas al infinito, para que Jesús se manifieste a través de ellas"24.

Los religiosos trabajamos, con frecuencia, a un ritmo anormal. Nos quejamos de activismo y da la impresión de que no podemos detener esa avalancha de compromisos que se nos vienen encima. Nos acosan tantas urgencias inaplazables de todo tipo, y a la larga, nos desfondamos, apare-

\footnotetext{
${ }^{24}$ J. VANIER, Comunidad: lugar de perdón y fiesta, Narcea, Madrid 19834, p. 220.
} 
cemos duros, funcionarios, cumplidores sí, pero sin alma. Y a veces, cansados, agotados, quemados. Nos conviene escuchar la invitación de Jesús: "vengan ustedes solos a un sitio tranquilo a descansar un poco, porque eran muchos los que iban y venían y ni para comer tenían tiempo" (Mc 6,30-31).

Por otro lado, la comunidad es siempre conflictiva. Si bien es verdad que no podemos vivir aislados, que necesitamos de la comunidad ("es mejor comer con dientes careados que comer sin dientes") ésta es conflictiva por naturaleza: distintos pareceres, distintos grados de madurez psicológica y vocacional, experiencias habidas, educación... Pero lo importante para nosotros no es constatar que hay conflictos, sino saber cómo afrontarlos. Por encima de los problemas, cualquier comunidad es conflictiva porque su problema de fondo -cómo hacer unidad desde la diversidad-es un problema real. La tendencia a realizarse de manera libre e individual hay que compaginarla con la tendencia a la unidad y a la dependencia del grupo. ¿Cómo ser individuales sin ser individualistas? En esto debe primar el sentido de pertenencia y el sentido de individuación. Si no se resuelve esta aparente antinomia estallará la lucha por el poder... y adiós comunidad. Si no se tiene un sentido de pertenencia claro, uno seguirá sus deseos narcisistas. No suele faltar este sentido, pero la comunidad debe fomentar el criterio de individuación, reconocer que se es distinto, con nombre propio, complementario... Individualidad no significa individualismo ${ }^{25}$. Finalmente, hay que saber que nunca tendremos una comunidad perfecta. No se puede identificar utopía con realidad, como no se puede identificar el camino con la meta.

\subsection{Reflexión}

La gente nos tiene que ver felices. No hay cosa que más atraiga que ver a una persona libre y feliz. En muchos ambientes, la gente lo tiene todo, pero no es feliz. Siempre anda a la búsqueda de llenar el hueco, ese "algo" que le falta. Y cuando decimos felices decimos contentos, centrados, alegres... con ese signo de Dios natural, sencillo y transparente que el pueblo percibe siempre en los/as religiosos/as. Más preocupados por ser que por hacer, porque hace más por el Reino un político que toma decisiones acertadas, que lo que puedan hacer todos los religiosos juntos. Pero el político intenta cambiar las cosas "de fuera hacia dentro", en cambio, los religiosos intentamos cambiar las cosas "de dentro hacia fuera". Es decir, lo importante no es lo que hacemos, sino lo que somos. Acentuando

25 Cf. A. Manenti, Vivir en comunidad, pp. 14-17. 
lo que somos podemos cambiar el mundo desde dentro. Lo que hacemos es empujar el carro en la dirección del Reino. Lo que hagamos vale como signo de que estamos por la vida, por la paz, por el amor, por la justicia, por el bien, por la verdad, en definitiva... por la fraternidad universal, sin exclusión alguna. De la misma manera que Jesús no solucionó el problema del hambre o de la salud, sino que sus milagros son signos del Reino que "ya está en medio de ustedes" (Mt 12,28 par.). Ser fermento, sal, luz, lámpara en alto y fieles; ese es nuestro reto, sabiendo que la pobreza y tantos otros males, siempre estarán ahí, para quien quiera verlos.

En realidad, no se trata propiamente de una cuestión de equilibrio, sino que debe tener preeminencia la oración sobre la actividad. No se puede citar de pasada el Evangelio; "nadie puede dar lo que no tiene". De tanto dar terminamos en pozos secos. En vez de trasmitir entusiasmo, terminamos en funcionarios. Actividad, sí; pero tiempo de oración, de estudio, de celebración, de silencio interior, también.

La Biblia entiende por "espiritual” el don del Espíritu que nos hace reconocer a Jesucristo como Señor y Salvador. La comunidad religiosa es excéntrica, misionera: no existe para afirmarse a sí misma, sino para perderse al servicio del Reino. Sin la referencia al mundo no tiene sentido. Pero tampoco la comunidad religiosa sería la comunidad del Espíritu, si en ella no hubiera lugar para la oración y la contemplación, para la lectura sosegada, para los carismas personales, para el crecimiento en la relación interpersonal, en la comunión, para la auténtica libertad.

\section{E. CONCLUSIONES: ¿VUELTA AL EdÉN?}

1) El desafío de la VR hoy es volver a Jesús. Esa es también la terapia para nuestras llagas. Nuestra crisis debe apuntar hacia delante y adelante sólo está Jesús. En el fondo la VR pretende volver al sueño de Dios expresado en la utopía mítica del jardín del Edén, es decir, de la humanidad confiada, transparente y recíprocamente amorosa, tal como Dios la creó. Pues bien, esta humanidad nunca se expresó más perfectamente que en Jesús, el nuevo Adán (cf. GS 22a). Nuestra vocación es volver a ese Jesús, renunciando a todo lo que nos aleja de Él. Y creo que nos ha pasado lo que a la Virgen de Copacabana, el antiguo santuario agustino de Bolivia. Despojada de toda vestimenta es una talla preciosa, pero lleva encima tantas telas lujosas que lo único que aparece es su carita aislada como una estrella en la noche. Por lo tanto, vuelta a la desnudez, la desnudez de Belén, la desnudez del Gólgota, la desnudez de la 
Pascua, la libertad de Jesús para el mundo. La desnudez espiritual nos llevará a una radicalización de opciones, y todo porque creemos que el bautismo es cosa seria y que implica la totalidad del ser, que es posible morir y renacer realmente en Cristo.

2) Jesús resucitado nos invita a volver a Galilea para verlo (cf. Mc 16,7). Volver al primer amor (cf. Ap 2,4). Esa bendita ignorancia del primer paso, la primera seducción. Galilea es la liberación de tantas cosas superfluas y superficiales... Que nos basta lo sencillo y lo profundo. Ser libres para adorar simplemente "en espíritu y en verdad" (Jn 4,23). Todo esto nos plantea la exigencia fundamental de toda vida consagrada: la contemplación. La raíz de toda VR es mística. Si lo que nos anima no es una experiencia real del Señor, todo lo demás es sencillamente absurdo. Volver a lo que buscaban los primeros llamados: la morada de Cristo (cf. Jn 1,38). El autor del Apocalipsis dice: "Tengo contra ti que has perdido tu amor primero" (Ap 2,4). Lo que motiva la frustración es la conciencia de haber perdido el amor primero. En resumen: el desafío de volver a Jesús implica reconstruir con valentía una coherencia de vida en torno a Jesús. El terreno privilegiado de este testimonio y esta vuelta a Jesús, es la vida comunitaria en fraternidad.

3) Hay una VR que agoniza porque es irrecuperable, pero también hay una VR que debe renacer como Nicodemo, siendo viejos (cf. Jn $3,4)$. No podemos pretender grandes "falanges religiosas", la VR es minoritaria por definición. Estamos en el tiempo apasionante del riesgo pionero, de los que se compran el tema de la resurrección y se animan mutuamente en la carrera hacia el sepulcro vacío. Este es un tiempo de tempestad y de intemperie, es tiempo de Cristo. No resistirán las casas construidas sobre arena, sino las ancladas en la roca de Cristo arquitecto (cf. Mt 7,24-27). "Si el Señor no construye la casa..." (Sal 126). Es tiempo para inspirados y no para funcionarios, para místicos, para quienes inauguran sin saberlo una nueva manera de ser Iglesia, como les ha pasado a todos los grandes fundadores. La VR ha de ser el aliento de Dios frente al sector oprimido, ha de dignificar con su presencia, ha de ser la mano de Dios que está presente, que anima, que da esperanza a los pobres.

4) Hoy nuestras comunidades han cambiado y para bien. Hemos pasado de un tenor de vida muy estructurado a otro más dinámico $y$ flexible; de un estilo de vida que gravitaba sobre un comporta- 
miento regular a otro en que se da paso a las relaciones interpersonales; de una vida marcada por actos comunes a una comunidad de vida rica en relaciones, donde cobra más importancia la amistad, el diálogo, la acogida y la aceptación mutua, la valoración y el respeto, la realización gozosa de cada uno; de una presencia física a una compenetración espiritual; de más unidad y menos uniformidad; más preocupados por la koinonia que por el rendimiento; menos "comunidad estufa con castañas calientes" y más comunidad orientada hacia la misión.

5) Dificultades: falta de conciencia práctica de que somos convocados por el Señor. Construir una fraternidad nos exige integrar nuestra existencia con la de otros que no hemos elegido, pero que sí ha elegido el Señor para nosotros; esto significa que los demás, tal como son, son un don del Señor para mí (cf. CdC 29), un don necesario en el proyecto de vocación que el Señor nos dio. Hasta el punto que uno siente que no puede realizarse según el plan de Dios si no es con los otros. Sólo desde la conciencia de que somos convocados por el Señor a vivir con Él y en Él, se puede aspirar a la aceptación mutua que nos hace capaces de amar radicalmente y compartir el ideal de Cristo.

6) Nada se construye, y menos una comunidad, si no es desde la sinceridad. Cuando hay confianza y sinceridad abrimos el camino de la intimidad. Nada construye tanto una comunidad como la transparencia. Las máscaras sólo sirven para el teatro. Es evidente que a muchas de nuestras comunidades les falta la unión de corazones (con-cordia), de la que debemos ser signo. Y la alegría que es la medida exacta de dicha unión; que hay un exagerado pudor y una gran distancia aunque las personas lleven conviviendo muchos años juntas. Antes la formación estaba encaminada a la unidad por la sumisión más que por la participación. El principio vital unificador de los miembros de la comunidad es el Espíritu. La amistad es necesaria en el mayor grado posible. La afinidad de caracteres es un factor que hay que tener en cuenta. Pero el polo aglutinante de la comunidad siempre será el Espíritu del Señor. Él nos ha llamado a seguirle con otros. Pero nadie aguanta por su propio esfuerzo estar todo el día con otros. Es necesario oxigenarse con la soledad y la oración personal.

7) ¿Es difícil seguir a Jesús? Sí y no. Realmente no es para débiles de espíritu, pero si Él llama da los medios para seguirle. Falta la deci- 
sión nuestra que es lo que no aportó el joven rico cuando le llamó Jesús (cf. Mc 10,17-22 par.). Nos gustaría un certificado de que valemos, de que servimos para esto; queremos ver claro y la VR es aventura, riesgo. Nos atenaza el miedo, queremos estar seguros... por otra parte, nos vemos tan lejos de la perfección que anhelamos, que viene el desánimo. Hay que dar pasos adelante, decir sí y confiar: quien dice sí a Dios, como María de Nazaret, recibe mucho más de lo que ofrece: "el ciento por uno y después la vida eterna" (Mc 10,30 par.). Y no nos llama porque somos santos, sino para que lo seamos; ni llama a los preparados, sino que prepara a los elegidos.

8) Los hermanos que son ejemplo favorecen la coexistencia del grupo, el que ha crecido puede ayudar a crecer a los demás. Y los que no son ejemplo... queda el dicho del Evangelio: "de dos que están en el campo, uno será tomado y otro dejado..." (Mt 24,39). "Hay monjes falsos... pero no perece la fraternidad piadosa por esos que profesan lo que no son" ${ }^{26}$, dice Agustín.

9) "La voluntad de Dios no es un misterio por lo menos en cuanto atañe al hermano y se trata del amor" (E. Käsemann). El seguimiento de Jesús no fue una experiencia exigida a un grupo de selectos; a todos invitó a amar sin fronteras, a perdonar "setenta veces siete" (Mt 18,22), a venderlo todo para comprar el tesoro ${ }^{27}$, sólo que los religiosos por la profesión nos compramos el campo del tesoro (cf. Mt 13,44).

10) La fuerza no es la comunidad en sí, sino los valores que vive la comunidad. Es decir, lo que hace crecer es la adhesión personal a unos valores. Y una vez orientados y aceptados los valores, podemos organizarnos a su luz: el seguimiento radical de Jesús. Aquí tan erróneo es frustrar a la persona, como darle todos sus caprichos. Por tanto, un no a la política permisiva y un sí a la política del discernimiento comunitario. El centro nunca será el universo humano, ni siquiera la comunidad, sino los valores que dan solidez a la comunidad y a las personas que optan por ella. Esto implica muchas veces ir donde no quería ir, o hacer lo que no me agrada, y no por obligación, sino por libre aceptación.

${ }^{26}$ SAn Agustín, Comentario a los Salmos 132,4, p. 466.

${ }^{27}$ Cf. R. Alonso, La aventura de seguir a Jesucristo (Creer y Crecer 10), FAE, Madrid 2005, pp. 2-3. 